\title{
Sustaining "Meaningful Use" of Health Information Technology in Low-Resource Practices
}

Lee A. Green, $M D, M P H^{1}$

Georges Potworowski, $\mathrm{PbD}^{2}$

Anya Day, MPH ${ }^{3}$

Racbelle May-Gentile, MPA ${ }^{3}$

Danielle Vibbert, $\mathrm{MPH}^{3}$

Bruce Maki, MA

Leslie Kiesel ${ }^{3}$

'Department of Family Medicine, University of Alberta, Alberta, Canada

${ }^{2}$ Health Policy, Management, and Behavior, The University at Albany - SUNY, New York, New York

${ }^{3}$ Altarum Institute, Ann Arbor, Michigan

\begin{abstract}
PURPOSE The implementation of electronic health records (EHRs) has been extensively studied, but their maintenance once implemented has not. The Regional Extension Center (REC) program provides implementation assistance to priority practices - those with limited financial, technical, and organizational resources-but the assistance is time limited. Our objective was to identify potential barriers to maintenance of meaningful use of EHRs in priority primary care practices using a qualitative observational study for federally qualified health centers (FQHCs) and priority practices in Michigan.
\end{abstract}

METHODS We conducted cognitive task analysis (CTA) interviews and direct observations of health information technology implementation in FQHCs. In addition, we conducted semistructured interviews with implementation specialists serving priority practices to detect emergent themes relevant to maintenance.

RESULTS Maintaining EHR technology will require ongoing expert technical support indefinitely beyond implementation to address upgrades and security needs. Maintaining meaningful use for quality improvement will require ongoing support for leadership and change management. Priority practices not associated with larger systems lack access to the necessary technical expertise, financial resources, and leverage with vendors to continue alone. Rural priority practices are particularly challenged, because expertise is often not available locally.

CONCLUSIONS Priority practices, especially in rural areas, are at high risk for falling on the wrong side of a "digital divide" as payers and regulators enact increasing expectations for EHR use and information management. For those without affiliation to maintain the necessary expert staff, ongoing support will be needed for those practices to remain viable.

Ann Fam Med 2015;13:17-22. doi: 10.1370/afm.1740.

\section{BACKGROUND}

B arriers to implementation of electronic health records (EHRs) in primary care have been a subject of concern and study for over a decade. ${ }^{1-11}$ When "meaningful use"12 of EHRs became an explicit federal policy goal through establishment of the Medicare and Medicaid EHR Incentive Program under the Health Information Technology for Economic and Clinical Health (HITECH) Act of $2009{ }_{1}^{13}$ the special challenges faced by primary care practices with limited resources were recognized. These practices represent a critical demographic in health care reform. Thus, when the Regional Extension Center (REC) for Health Information Technology Adoption program was created by the Office of the National Coordinator for Health Information Technology (ONC), the "priority primary care physician" designation was created to identify practices in particular need of assistance in overcoming barriers to health information technology (IT) adoption, implementation, and attainment of meaningful use.

In this paper, we consider low-resource practices to be primary care practices that have little or no internal professional management or information technology expertise and little or no access to external expertise in these areas. That may be due to a lack of financial resources, a lack of 
affiliation with larger organizations that could provide such expertise or subsidize access to it, geographic location where such expertise is scarce or absent, or a combination of these factors.

By its very nature, health IT involves periodic updates that bring changes in functionality and formatting, may have bugs, and often require new training. Because updates can disrupt workflow, the maintenance phase of health IT is not only critical to continued meaningful use, it is also a more dynamic and adaptive process than what is typically involved in the maintenance of a one-off implementation. Maintaining meaningful use of EHRs and other health IT requires hardware support, ongoing problem solving to deal with technical glitches and adapt to upgrades, and assistance in dealing with rising expectations and requirements for reporting and quality improvement based on data from these systems.

Published research to date has largely addressed health IT implementation. Neither the existing literature nor the REC program clearly addresses the unique challenges associated with maintaining use of health IT, and especially not in low-resource practices.

This challenge became salient to us in the course of 2 projects we conducted concurrently: a project providing cognitive task analysis ${ }^{14}\left(\mathrm{CTA}_{i}\right.$ see Methods) consultations to federally qualified health centers (FQHCs) in Michigan to assist them with health IT implementation (AHRQ 1R18 HS018170-01) and the ONC-funded REC program of the Michigan Center for Effective IT Adoption (M-CEITA). The projects were not related, but we noticed similar concerns relating to maintenance of health IT arising in each. We believed these concerns had important and time-sensitive implications for US health care policy. We therefore pooled our experience with and qualitative data from these 2 projects to identify themes related to maintenance and meaningful use of health IT in low-resource practices.

\section{METHODS}

\section{Project 1: CTA Consultations for Health IT Implementation}

CTA is a set of highly structured qualitative methods used for, among other things, understanding and improving the performance of teams of knowledge workers. It has an extensive track record in a number of fields..$^{15}$ We conducted detailed CTAs using the Task Diagram and Team Audit methods ${ }^{14,16}$ to understand the organizational routines of 3 rural FQHCs in Michigan, as well as to understand important contextual factors, culture, and interactional dynamics in the context of implementation of a clinical quality management system (CQMS)..$^{17}$ The FQHCs were in different regions of the state, and varied widely in size and structure. We provided consultation reports with site-specific clinical workflow and organizational recommendations for facilitating the CQMS implementation and observed the impact of the CTA consultations on the FQHCs' implementation processes.

For the present analysis we reexamined the data, which was coded using an established framework for themes involved in decision making and change management (eg, sense making and learning, problem detection and monitoring). ${ }^{14,15,18}$ We looked for themes informative about each practice's ability to maintain and meaningfully use health IT. The analysis was done by individual immersion and crystallization, followed by team reconciliation in weekly meetings over 4 weeks.

\section{Project 2: Analysis of M-CEITA Health IT Implementation Specialists' Experiences}

Since 2010, M-CEITA has been delivering direct, in-office technical assistance to over 4,000 providers across Michigan in the areas of engagement $t_{i} E H R$ selection, planning, and implementation, and meaningful use of health IT.

M-CEITA's ONC-funded services are targeted to priority primary care providers working in small practices, community health centers, FQHCs, rural health centers, critical access hospitals, and other care settings primarily serving the underserved across Michigan. Hence, M-CEITA's implementation specialists have developed a detailed understanding of practice workflows and the many barriers that low-resource practices face in implementing and maintaining health IT.

For Project 2, we conducted 70- to 90-minute semistructured interviews with $6 \mathrm{M}$-CEITA implementation specialists who provided implementation assistance to and evaluated effectiveness in low-resource practices in rural and urban settings across the state. The implementation specialists were chosen for maximum variation in the geographic areas of the state and the sociodemographic characteristics of the practices with which they worked, and within that selection for the maximum years of experience. The interview guide was developed by the study team based on our experience in Project 1, but before the formal analysis described above was completed on Project 1's data. The implementation specialists were encouraged to voice their insights beyond those solicited in the interview guide.

The team conducted 1 round of individual immersion and crystallization followed by weekly team reconciliation meetings specifically targeted to identify major themes relevant to implementation and maintenance, from the interview data for Project 2. This was done concurrently with the Project 1 analysis described above, and the major themes were reconciled 
with those from the Project 1 analysis. This resulted in a single set of identified major themes.

\section{RESULTS}

Our findings concerning barriers to implementation were very consistent with those in the existing literature ${ }^{1,2,6,7,9}$ (Table 1), with 1 addition: many practices needed help with even understanding the meaningful use provisions and requirements. The consistency of these findings with those of many previous studies by others is presented as an indicator of the trustworthiness of our data sources and analysis, but implementation is not the focus of this paper, so it will not be addressed further. The focus will instead be on those themes with particular implications for maintenance of meaningful use - the area that is poorly addressed in existing literature.

The 4 themes that emerged related to successful maintenance of health information technology were these:

- Managerial, organizational, and change management expertise

- Technology support

- Vendor relationships

- Special challenges facing rural practices

Managerial and organizational expertise was a prominent theme throughout both projects. Lowresource practices benefitted substantially from direct assistance in change management, business process planning, and other professional managerial issues. These practices typically did not have the scale or resources to support a trained professional manager and could not afford to engage management consultants.

Technology support issues included selection of hardware and EHR software, configuration, use of features such as reporting, and maintenance of security. The REC provided implementation support in all these areas and, in Project 1, we provided some support for reporting functions for population management. As we said above, computer and network hardware will inevitably become outdated or fail and have to be replaced, EHR updates will be released, regulatory and payer expectations for functions supported by the EHR will evolve, and security threats will continue to change rapidly. The technology subthemes that emerged in our data were that low-resource practices did not have the internal skills to select optimal replacement or upgraded hardware, to train staff beyond the brief instruction offered by vendors in the use of new versions of their EHRs or when new staff join, or to maintain system and network security as new threats emerge.

Vendor relationships were a prominent area of concern. In Project 1, inadequate vendor training and
Table 1. Barriers to Implementation of CQMS Identified in Existing Literature

\begin{tabular}{|c|c|}
\hline Barrier Type & Typical Issues \\
\hline Situational & $\begin{array}{l}\text { Time needed to implement, records conver- } \\
\text { sion, adverse effect on workflow or efficiency, } \\
\text { organizational structure, organizational culture, } \\
\text { incentives }\end{array}$ \\
\hline $\begin{array}{l}\text { Cognitive/ } \\
\text { psychological }\end{array}$ & $\begin{array}{l}\text { Lack of belief in value, need for control, anxiety } \\
\text { over change, anxiety over technology }\end{array}$ \\
\hline Liability & Privacy, security management, data integrity \\
\hline Knowledge & Ability to evaluate and select systems, training \\
\hline Financial & $\begin{array}{l}\text { Start-up costs, training costs, uncertain or mis- } \\
\text { aligned return on investment }\end{array}$ \\
\hline Technology & $\begin{array}{l}\text { Technical support, complexity, inflexibility of } \\
\text { systems, customization limitations, reliability } \\
\text { problems, data exchange problems }\end{array}$ \\
\hline Workforce & $\begin{array}{l}\text { Skillsets of physicians, staff skills, managerial/ } \\
\text { organizational support, leadership }\end{array}$ \\
\hline
\end{tabular}

other technical support issues were significant barriers to effective integration of the CQMS system into clinical workflow. In Project 2, we found that REC implementation specialists expended considerable effort on behalf of practices in dealing with issues of vendor responsiveness, vendor knowledge and interpretation of meaningful use requirements, business negotiation, and staff training. In both studies we found that lowresource practices simply did not have the leverage to command vendor responsiveness to their needs.

Rural practices faced the same lack of financial resources as urban underserved practices, but they also faced challenges unique to their geography. They often had unreliable Internet service, for example, resulting in a greater need for hardware consultants, but in many rural areas skilled hardware consultant services simply do not exist. Similarly, while both urban and rural practices struggled to pay for software, security, and training consultation, rural practices often found such services nonexistent in their areas.

\section{DISCUSSION}

Our findings suggest that, without ongoing support addressing the themes identified above, low-resource practices may achieve Stage 1 meaningful use only to fall by the wayside, resulting in an ever-widening "digital divide" as better-resourced practices continue to increase the sophistication of their health IT operations. The advances in clinical processes expected for Stage 2 and Stage 3 meaningful use will strain both the technological expertise and management expertise of low-resource practices.

The management expertise deficit is a particular risk. Stage 1 (Table 2) was by definition the simplest and most straightforward of the stages of meaning- 
ful use, yet management in many practices struggled to understand the long list of detailed measures and how they applied to their practices. The implementation specialists needed to devote a major portion of their work to educating both practices and vendors about meaningful use. Stage 1 strongly emphasized implementation and documentation; thus, in many cases the practices did not actually need to make many clinical process changes to meet the requirements. Nevertheless, practices needed so much help in meeting Stage 1 requirements that they received relatively little coaching or education on change management or on the types of clinical process and quality improvement changes they will be expected to make in order to meet future stages of meaningful use. Yet just as the more complex stages of meaningful use are beginning and the need for change management skills is increasing significantly, funding for the REC program that could help these practices access the needed expertise is going away.

In terms of technology, staff training is a particular challenge. Vendors provide limited training before or during implementation. Stage 2 meaningful use (Table 3) will require much more sophisticated use of health IT, well beyond what they were trained to do in implementation, but low-resource practices are not able to purchase additional training time. As we said above, they are often not even able to train new staff adequately on existing technology as they lose trained staff through turnover.

When support for the implementation specialists ends, low-resource practices not affiliated with larger, more influential organizations will not have agents to intercede with vendors on their behalf. Vendor capacity is already stretched, so larger customers are likely to soak up all the support available, leaving lowresource practices in the cold.

Two resource issues underlie the challenges described above: financial and operational. Operationally, low-resource practices lack both the leverage with vendors and the managerial and technical expertise that larger group practices have. Financially, lowresource practices lack the funding to procure those operational elements from outside.
The implementation specialists from the RECs provided temporary operational resources (technical and managerial consultation, vendor intercession) at little or no financial cost to ensure the most vulnerable groups were able to meet the requirements, but without continued or alternative operational and financial support, many of these clinics will not be able to navigate the changes necessary to maintain the evolving demands of their health IT systems. As a result, these low-resource clinics will face Medicare downward payment adjustments of as much as $5 \%$ for noncompliance, inability to exchange health information between systems, limited reporting capability, missed incentive payments, and poor ability to support clinical quality improvement. The limitations on reporting and quality improvement capabilities will affect clinics' ability to secure quality incentive payments from other payers as well. Since these clinics are often marginally financially viable to begin with, the Medicare payment and private-payer incentive losses will likely threaten their ability to remain open at all.

Solutions to the lack of health IT maintenance capacity in low-resource practices must address both their financial and operational needs. The initial idea for the RECs was that they would become self- 


\section{Table 3. Meaningful Use Stage 2 Core and Menu Measures}

\begin{tabular}{|c|c|c|}
\hline No. & Measure & Threshold \\
\hline 1 & $\begin{array}{l}\text { Computerized provider order entry used for medication, laboratory, } \\
\text { and radiology orders }\end{array}$ & $60 \%, 30 \%, 30 \%$ \\
\hline 2 & Permissible prescriptions generated and transmitted electronically & $50 \%$ \\
\hline 3 & Demographics recorded as structured data & $80 \%$ \\
\hline 4 & Changes in vital signs recorded and charted as structured data & $80 \%$ \\
\hline 5 & Smoking status recorded as structured data for patients $\geq 13$ years & $80 \%$ \\
\hline 6 & $\begin{array}{l}\text { Clinical decision support used to improve performance on high- } \\
\text { priority health conditions }\end{array}$ & Yes \\
\hline 7 & $\begin{array}{l}\text { Patients given the ability to view, download, and transmit their } \\
\text { health information within } 4 \text { days of its availability to the provider }\end{array}$ & $50 \%, 5 \%$ \\
\hline 8 & Patients given clinical visit summaries within 1 business day of a visit & $50 \%$ \\
\hline 9 & Electronic health information protected by appropriate technology & Yes \\
\hline 10 & Clinical laboratory test results recorded as structured data & $55 \%$ \\
\hline 11 & Condition-specific patient lists generated & Yes \\
\hline 12 & $\begin{array}{l}\text { Clinically relevant information used to identify patients who should } \\
\text { receive reminders for preventive or follow-up care }\end{array}$ & $10 \%$ \\
\hline 13 & Appropriate, patient-specific education resources identified & $10 \%$ \\
\hline 14 & Medication reconciliation performed & $50 \%$ \\
\hline 15 & Transition of care summary provided for each transition of care & $50 \%, 10 \%$ \\
\hline 16 & $\begin{array}{l}\text { Ongoing submission of electronic immunization data to immuniza- } \\
\text { tion registries }\end{array}$ & Yes \\
\hline 17 & $\begin{array}{l}\text { Secure electronic messaging used to communicate with patients } \\
\text { concerning relevant health information }\end{array}$ & $5 \%$ \\
\hline \multicolumn{3}{|c|}{ Menu measures (providers must meet 3 of 6 ) } \\
\hline 1 & $\begin{array}{l}\text { Ongoing submission of syndromic surveillance data to public } \\
\text { health agencies }\end{array}$ & Yes \\
\hline 2 & Electronic progress notes entered into patient records & $30 \%$ \\
\hline 3 & $\begin{array}{l}\text { Imaging results are accessible through certified electronic health } \\
\text { record technology }\end{array}$ & $10 \%$ \\
\hline 4 & Patient family health histories recorded as structured data & $20 \%$ \\
\hline 5 & $\begin{array}{l}\text { Ongoing submission ofcancer case information to a public health } \\
\text { central cancer registry }\end{array}$ & Ongoing \\
\hline 6 & $\begin{array}{l}\text { Ongoing submission of specific case information to a specialized } \\
\text { registry }\end{array}$ & Ongoing \\
\hline
\end{tabular}

are stable organizations and well positioned to address maintenance. Similarly, health systems that now provide operational and financial support to their own practices might be granted funding to take low-resource practices under their wings. Both of these approaches avoid creating new long-term entities, but may not help rural non-FQHC practices in areas of high need.

In some cases state Medicaid agencies have worked with RECs to obtain funding from CMS using Health Information Technology Implementation Advance Planning Documents. ${ }^{21}$ These funds have been used both to expand Stage 1 meaningful use support to providers outside the ONC priority provider designation (ie, specialists with high Medicaid patient volumes) and to help a limited number of providers in pursuit of Stage 2 meaningful use. The funding to date has done more to extend reach to additional providers than to support the continued engagement of services for maintenance. This mechanism, however, could be used to enable state Medicaid agencies to provide operational and financial support for main- sustaining through user fees. That appears to be unrealistic, however. The practices with the greatest need tend to have the least ability to pay.

One long-term solution would be to make the REC program, like the agricultural extension service program ${ }_{1}^{19}$ an open-ended effort. The crucial component of maintenance could then be added to the existing implementation focus of the RECs. This approach would mean creation and support of a new set of long-term organizations, but has the advantage of broad reach across geography and circumstance. Recent recommendations from the President's Council of Advisors on Science and Technology have supported this approach. ${ }^{20}$

Another approach, at least for FQHCs and Community Health Centers, might be to provide the Primary Care Associations with incremental resources to provide the needed operational support at no cost to member practices. The Primary Care Associations tenance. This approach, like others above, would take advantage of existing, stable organizations, and it would direct support to the practices most in need. Its disadvantage is that states vary quite widely in their support for their Medicaid programs. Practices in some states might benefit while those in other states receive little or no help.

Ultimately, any long-term stable solutions must address the operational and financial needs of lowresource primary care practices in general, and the additional needs of rural practices in particular. Absent that, the multifaceted challenge of health IT maintenance will almost inevitably overwhelm low-resource practices. The operational and financial consequences of falling behind in maintenance will mean lower quality care for the patients in areas these practices serve-or quite possibly no care at all.

To read or post commentaries in response to this article, see it online at http://www.annfammed.org/content/13/1/17. 
Key words: primary health care; electronic health records; health information technology; American Recovery and Reinvestment Act; safetynet providers; rural health services; meaningful use; regional extension centers

Submitted June 20, 2014; submitted, revised, October 11, 2014; accepted October 22, 2014.

Funding support: Agency for Healthcare Research and Quality, grant no. R18 HS018170-01

\section{References}

1. Boonstra A, Broekhuis M. Barriers to the acceptance of electronic medical records by physicians from systematic review to taxonomy and interventions. BMC Health Serv Res. 2010;10:231. 10.1186/1472-6963-10-231.

2. Greiver M, Barnsley J, Glazier RH, Moineddin R, Harvey BJ. Implementation of electronic medical records: theory-informed qualitative study. Can Fam Physician. 2011;57(10):e390-e397.

3. Hersh W. Health care information technology: progress and barriers. JAMA. 2004;292(18):2273-2274. 10.1001/jama.292.18.2273.

4. Johnson KB. Barriers that impede the adoption of pediatric information technology. Arch Pediatr Adolesc Med. 2001;155(12):13741379.

5. Kaplan B, Harris-Salamone KD. Health IT success and failure: recommendations from literature and an AMIA workshop. J Am Med Inform Assoc. 2009;16(3):291-299. 10.1197/jamia.M2997.

6. Ludwick DA, Doucette J. Adopting electronic medical records in primary care: lessons learned from health information systems implementation experience in seven countries. Int J Med Inform. 2009;78(1):22-31. 10.1016/j.jijmedinf.2008.06.005.

7. McAlearney AS, Sieck C, Hefner J, Robbins J, Huerta TR. Facilitating ambulatory electronic health record system implementation: evidence from a qualitative study. BioMed Res. Int. 2013;2013:629574. 10.1155/2013/629574.

8. McGinn CA, Grenier S, Duplantie J, et al. Comparison of user groups' perspectives of barriers and facilitators to implementing electronic health records: a systematic review. BMC Med. 2011:9(4):46. 10.1186/1741-7015-9-46.

9. Miller RH, Sim I. Physicians' use of electronic medical records: barriers and solutions. Health Aff (Millwood). 2004;23(2):116-126.
10. Poon EG, Blumenthal D, Jaggi T, Honour MM, Bates DW, Kaushal R. Overcoming barriers to adopting and implementing computerized physician order entry systems in U.S. hospitals. Health Aff (Millwood). 2004;23(4):184-190.

11. Wears RL, Berg M. Computer technology and clinical work: still waiting for Godot. JAMA. 2005;293(10):1261-1263. 10.1001/ jama.293.10.1261.

12. Centers for Medicare \& Medicaid Services (CMS) Incentive Programs. http://www.cms.gov/EHRIncentivePrograms/01_Overview. asp. Accessed Sep 22, 2014.

13. American Recovery and Reinvestment Act of 2009. PL 111-5, Title XIII.

14. Potworowski G, Green LA. Cognitive Task Analysis: Methods to Improve Patient-Centered Medical Home Models by Understanding and Leveraging its Knowledge Work. Agency for Healthcare Research and Quality, Publication No. 13-0023-EF. http://pcmh. ahrq.gov/page/cognitive-task-analysis-methods-improve-patientcentered-medical-home-models-understanding-and $\# \mathrm{~h}=$. Published Mar 2013.

15. Crandall B, Klein GA, Hoffman RR. Working Minds: A Practitioner's Guide to Cognitive Task Analysis. Cambridge, MA: MIT Press; 2006.

16. Klein GA, Militello L. The Knowledge Audit as a method for cognitive task analysis. In: Lipshitz R, Brehmer B, eds. How Professionals Make Decisions. Mahwah, NJ: Lawrence Erlbaum Associates; 2005.

17. Advisory Board Company-Crimson Care Registry. http://www. advisory.com/Technology/Crimson-Care-Registry. Accessed Oct 8, 2012.

18. Schraagen MJ, Klein G, Hoffman RR. The macrocognition framework of naturalistic decision-making. In: Naturalistic DecisionMaking and Macrocognition. Burlington, VT: Ashgate; 2008:3-25.

19. NIFA UE. NIFA Extension page. http://www.csrees.usda.gov/qlinks/ extension.html. Accessed Sep 7, 2014.

20. Executive Office of the President. President's Council of Advisors on Science and Technology. Report to the President Better Health Care and Lower Costs: Accelerating Improvement through Systems Engineering. http://www.whitehouse.gov/sites/default/files/microsites/ ostp/PCAST/pcast_systems_engineering_in_healthcare_-_may_2014. pdf. Published May 2014.

21. Department of Health and Human Services. Centers for Medicare $\varepsilon$ Medicaid Services. Center for Medicaid, CHIP and Survey $\&$ Certification. SMD\# 10-016: Guidance for Federal Funding for Medicaid Health Information Technology Activities. http://downloads.cms. gov/cmsgov/archived-downloads/SMDL/downloads/SMD10016.pdf. Publilshed Aug 17, 2010. 